\title{
Association of Common Variants in MMPs with Periodontitis Risk
}

\author{
Wenyang Li, ${ }^{1}$ Ying Zhu, ${ }^{2}$ Pradeep Singh, ${ }^{1}$ Deepal Haresh Ajmera, ${ }^{1}$ Jinlin Song, ${ }^{1}$ and Ping Ji ${ }^{1}$ \\ ${ }^{1}$ Chongqing Key Laboratory of Oral Diseases and Biomedical Sciences and College of Stomatology, Chongqing Medical University, \\ Chongqing 400016, China \\ ${ }^{2}$ Department of Forensic Medicine, Faculty of Basic Medical Sciences, Chongqing Medical University, Chongqing 400016, China
}

Correspondence should be addressed to Ping Ji; ckjiping136@163.com

Received 5 December 2015; Revised 18 February 2016; Accepted 16 March 2016

Academic Editor: Jacek Kurzepa

Copyright (C) 2016 Wenyang Li et al. This is an open access article distributed under the Creative Commons Attribution License, which permits unrestricted use, distribution, and reproduction in any medium, provided the original work is properly cited.

\begin{abstract}
Background. Matrix metalloproteinases (MMPs) are considered to play an important role during tissue remodeling and extracellular matrix degradation. And functional polymorphisms in MMPs genes have been reported to be associated with the increased risk of periodontitis. Recently, many studies have investigated the association between MMPs polymorphisms and periodontitis risk. However, the results remain inconclusive. In order to quantify the influence of MMPs polymorphisms on the susceptibility to periodontitis, we performed a meta-analysis and systematic review. Results. Overall, this comprehensive meta-analysis included a total of 17 related studies, including 2399 cases and 2002 healthy control subjects. Our results revealed that although studies of the association between $M M P-8-799 \mathrm{C} / \mathrm{T}$ variant and the susceptibility to periodontitis have not yielded consistent results, $M M P-1$ $(-1607 \mathrm{lG} / 2 \mathrm{G},-519 \mathrm{~A} / \mathrm{G}$, and $-422 \mathrm{~A} / \mathrm{T}), M M P-2(-1575 \mathrm{G} / \mathrm{A},-1306 \mathrm{C} / \mathrm{T},-790 \mathrm{~T} / \mathrm{G}$, and $-735 \mathrm{C} / \mathrm{T}), M M P-3(-11715 \mathrm{~A} / 6 \mathrm{~A}), M M P-8$ $(-381 \mathrm{~A} / \mathrm{G}$ and $+17 \mathrm{C} / \mathrm{G}), M M P-9(-1562 \mathrm{C} / \mathrm{T}$ and $+279 \mathrm{R} / \mathrm{Q})$, and MMP-12 (-357 Asn/Ser), as well as MMP-13 (-77 A/G, 11A/12A) SNPs are not related to periodontitis risk. Conclusions. No association of these common MMPs variants with the susceptibility to periodontitis was found; however, further larger-scale and multiethnic genetic studies on this topic are expected to be conducted to validate our results.
\end{abstract}

\section{Introduction}

Periodontitis being one of the most common forms of destructive periodontal disease in adults can be defined as bacterial plaque induced inflammation of the attachment apparatus of teeth and supporting structures, which initially manifests as gingivitis and is characterized by extension of inflammation from the gingiva into deeper periodontal tissues that if left untreated results in destruction of periodontium associated with progressive attachment loss and irreversible bone loss [1]. Currently, periodontitis is considered to be multifactorial disease, developing as a result of complex interactions between specific host genes and the environment [2]. Although periodontitis is initiated and sustained by bacterial plaque, host factors determine the pathogenesis and rate of progression of the disease [3].
Matrix metalloproteinases (MMPs) are a large family of metal-dependent extracellular proteinases which are responsible for the tissue remodeling and degradation of the extracellular matrix (ECM), including collagens, elastins, gelatin, matrix glycoproteins, and proteoglycans [4]. To date, at least 26 members of MMPs have been identified [5]. The majority of MMPs proteins are secreted as inactive proMMPs, which are subsequently processed by other proteolytic enzymes (such as serine proteases, furin, and plasmin) to generate the active forms. The proteolytic activities of MMPs are precisely controlled during activation from their precursors and inhibition by endogenous inhibitors, a-macroglobulins, and tissue inhibitors of metalloproteinases (TIMPs) or by nonselective synthetic inhibitors (batimastat, BB-94) [6].

Significant evidence suggests that MMPs comprise the most important pathway in the tissue destruction associated 
with periodontal disease [7]. And based on previous studies, dramatically elevated levels of MMP-1, MMP-2, MMP-3, MMP-8, and MMP-9 have been detected in gingival crevicular fluid, peri-implant sulcular fluid, and gingival tissue of periodontitis patients [8]. Likewise, recent studies have also shown that mRNA levels of MMPs are significantly increased in inflamed gingival tissue. MMPs activity may be regulated by interactions with their endogenous inhibitors (TIMPs) and posttranslational modifications, as well as at the levels of gene transcription [9]. Consequently, it can be hypothesized that functional polymorphisms in MMPs genes may affect MMPs expression or activity and, thus, may predispose to periodontal disease conditions.

According to some genotype analyses of single nucleotide polymorphisms (SNPs) in MMPs genes, they have shown increased frequency of several common MMPs SNPs in patients with periodontitis [10-13]. On the contrary, some other studies have demonstrated little or no association of these SNPs in MMPs genes with etiopathogenesis of periodontitis [14-17]. Despite comprehensive studies focusing on the association of gene polymorphisms with the susceptibility and/or severity of periodontitis, there exists a high degree of inconsistency and the results are inconclusive; therefore, for the purpose of deriving a more precise estimation of association between these MMPs SNPs and periodontitis risk, we performed a meta-analysis and systematic review of all eligible studies.

\section{Materials and Methods}

2.1. Protocols and Eligibility Criteria. The meta-analysis and systematic review reported here are in accordance with the Preferred Reporting Items for Systematic Review and MetaAnalyses (PRISMA) statement (Appendix S1 in the Supplementary Material available online at http://dx.doi.org/10.1155/ 2016/1545974). The research question for this study was formulated based on the PICO (population, intervention, comparison, and outcomes) criteria. The literature search was limited to original studies performed in humans on the association of matrix metalloproteinases SNPs with periodontitis risk.

2.2. Search Strategy. Studies addressing the correlations of MMPs genetic polymorphisms with the risk of periodontitis were identified by performing an electronic search in PubMed (1966 to May 2015), Medline (1950 to May 2015), and Web of Science databases (1900 to May 2015) by using the following search terms in PubMed: $((()(($ “Matrix Metalloproteinases" [Mesh]) OR Matrix Metalloproteinases) OR Matrix Metalloproteinase) OR MMPs) OR MMP)) AND ((((“"Polymorphism, Genetic" [Mesh]) OR Polymorphism) OR "Genetic Variation” [Mesh]) OR Genetic Variation) OR genetic variant $))$ AND $(((()(((($ (“Periodontitis” [Mesh]) OR Periodontitis) OR “Chronic Periodontitis" [Mesh]) OR Chronic Periodontitis) OR CP) OR "Aggressive Periodontitis" [Mesh]) OR Aggressive Periodontitis) OR AgP) OR "Periodontal Diseases" [Mesh]) OR Periodontal Diseases) OR PD). Other databases were searched with comparable terms suitable for the specific database. Furthermore, in order to identify any additional studies that may have been missed, a computer-assisted strategy based on manual searching of reference lists from potentially relevant reviews and retrieved articles was performed. Full texts of the relevant articles and studies published in English were retrieved and included to explore the association between MMPs polymorphisms and the susceptibility to periodontitis.

2.3. Selection of Studies. The studies included in the present meta-analysis and systematic review had to meet the following inclusion criteria: (a) studies used validated genotyping methods (such as PCR-RFLP and TaqMan) to measure the association of SNPs in MMP genes with periodontitis risk; (b) studies were in an appropriate analytical design, including case-control, cohort, or nested case-control; (c) studies were published in English; (d) the full text of studies was available, and (e) the data of studies were not duplicated in another manuscript. However, studies were excluded if they did not provide enough information on genotype frequency or did not report sufficient genotype distribution for calculation of odds ratios (ORs) and its variance. Besides, studies investigating the mixed population were excluded if they did not provide the detailed information for each ethnicity. Moreover, studies were also excluded if genotype distributions of control subjects were varied from Hardy-Weinberg equilibrium (HWE).

2.4. Data Extraction. To ensure homogeneity of data collection and to rule out the effect of subjectivity in data gathering, data extraction was performed independently by two investigators (Ying Zhu and Pradeep Singh), using a predefined protocol. Disagreements were resolved by iteration, discussion, and consensus. A series of items were collected for each trial, including first author's surname, publication year, country, ethnicity (Caucasian, Asian, or mixed (excluding the detailed ethnic results of mixed population in the original study)), type and severity of periodontitis, matching criteria of cases and controls, source of controls, allelic frequency in both cases and controls, genotyping methods, and also the genes and variants genotyped. Furthermore, the evidence of $\mathrm{HWE}$ in controls was verified through the application of an online software (http://www.oege.org/software/hwe-mr-calc.shtml). $p$ value less than 0.05 of HWE was considered to be significant.

2.5. Risk of Bias. Methodological quality was independently evaluated by two researchers (Pradeep Singh and Deepal Haresh Ajmera) according to the recently proposed Newcastle-Ottawa Scale (NOS) criteria for the quality assessment of case-control studies. To unravel potential systematic biases, a third investigator (Wenyang Li) performed a concordance study by independently reviewing all eligible studies; complete concordance was reached for all variables assessed. Briefly, the quality of each study was assessed by using the following methodological components: (1) subject selection; (2) comparability of subject; and (3) clinical outcome. Table 2 illustrates the details of each methodological item. NOS scores ranged from 0 to 9 , wherein a score of $\geq 5$ was regarded 
as high-quality study, while studies with scores $<5$ were classified as low-quality studies.

2.6. Heterogeneity. A test for heterogeneity (true variance of effect size across studies) was performed using a $Q$ test (to assess whether observed variance exceeds expected variance) to establish inconsistency in the study results. However, because the test is susceptible to the number of trials included in the meta-analysis, we also calculated $I^{2} \cdot I^{2}$, directly calculated from the $Q$ statistic, indicates the percentage of variability in effect estimates because of true heterogeneity, rather than sampling error. $I^{2}$ ranges from $0 \%$ to $100 \%$, with $0 \%$ indicating the absence of any heterogeneity. Although absolute numbers for $I^{2}$ are not available, values $<50 \%$ are considered low heterogeneity, and the effect is thought to be fixed. Conversely, when $I^{2}$ exceeds $50 \%$, then heterogeneity is thought to exist and the effect is random.

2.7. Statistical Analysis. The STATA version 11.0 (Stata Corp, College Station, TX, USA) software was used for metaanalysis. The strength of the association between MMPs SNPs and periodontitis risk was evaluated by ORs with their $95 \%$ confidence intervals (CIs) under different genetic models: the allele model (mutant allele versus wild allele), the codominant model (homozygous rare/heterozygous versus homozygous frequent and homozygous rare versus heterozygous), the dominant model (heterozygous + homozygous rare versus homozygous frequent), and the recessive model (homozygous rare versus heterozygous + homozygous frequent), as well as the additive model (heterozygous versus homozygous frequent + homozygous rare). In addition, subgroup analyses were stratified, when feasible, according to the type of disease, racial descent, severity of chronic periodontitis, and smoking habit, respectively. The $Z$-test was used to estimate the statistical significance of pooled ORs, and the Bonferroni correction was used to account for multiple testing in association analyses. When all genetic models were tested for each SNP, a corrected $p$ value $<0.01$ was considered statistically significant.

To estimate the pooled ORs, a fixed effects model (the Mantel-Haenszel method) was used initially, whereas the random effects model (DerSimonian and Laird method) was applied when evidence of significant heterogeneity was found across trials $\left(p<0.1\right.$ and $\left.I^{2}>50 \%\right)$. In order to evaluate the potential source of heterogeneity, a sensitivity analysis was performed through sequential removal of each included study. Publication bias was investigated using funnel plots, wherein the standard error of $\log (\mathrm{OR})$ was plotted against $\log (\mathrm{OR})$ for each study. Besides, funnel plot asymmetry was assessed with the Begg rank correlation test (Begg test) and the Egger linear regression approach (Egger test). $p$ values of less than 0.05 from the Egger's test were considered statistically significant. In addition, the results of the trials which could not be pooled through the meta-analysis were assessed using descriptive statistics.

\section{Results}

The flowchart for the process of including/excluding articles is shown in Figure 1. After abstracts were screened for relevance, 25 full-text studies, comprising chronic periodontitis (CP) and/or aggressive periodontitis ( $\mathrm{AgP})$, were comprehensively assessed against the inclusion criteria. Three studies were excluded because they were not in accordance with HWE $[10,18,19]$. Another four studies were excluded because they reported the results of mixed population but did not provide the detailed information for each ethnicity $[15,17,20,21]$. Besides, one more study was excluded due to insufficient data availability for calculating ORs and their variance [7]. Finally, 17 case-control studies, investigating the association of MMP-1 (-1607 1G/2G, $-519 \mathrm{~A} / \mathrm{G}$, and -422 $\mathrm{A} / \mathrm{T}), M M P-2(-1575 \mathrm{G} / \mathrm{A},-1306 \mathrm{C} / \mathrm{T},-790 \mathrm{~T} / \mathrm{G}$, and -735 C/T), MMP-3 (-1171 5A/6A), MMP-8 (-799 C/T, $-381 \mathrm{~A} / \mathrm{G}$, and $+17 \mathrm{C} / \mathrm{G}), M M P-9(-1562 \mathrm{C} / \mathrm{T}$ and $+279 \mathrm{R} / \mathrm{Q}), M M P-12$ $(-357 \mathrm{Asn} / \mathrm{Ser})$, and MMP-13 (-77 A/G and 11A/12A) with periodontitis risk, were included in this meta-analysis $[8,11-$ $14,16,22-32]$. And the characteristics and quality assessment of all included studies are summarized in Tables 1 and 2.

3.1. MMP-1. Table 3 and Figure 2 show the meta-analysis results of two SNPs in the MMP-1 gene, namely, $-16071 \mathrm{G} / 2 \mathrm{G}$ and $-519 \mathrm{~A} / \mathrm{G}$, under various genetic models. In Caucasians, we failed to identify any significant association of these two SNPs with the susceptibility to CP under all comparison models (Table 3; Figure 2). Besides, in Asian population, our results also demonstrated that there was no statistically significant association between $M M P-1-1607$ 1G/2G polymorphism and the risk of both $\mathrm{CP}$ and $\mathrm{AgP}$ (Table 3; Figure 2). Furthermore, analyses of individual polymorphism revealed no differences in distribution of $M M P-1-422 \mathrm{~A} / \mathrm{T}$ variant between $\mathrm{CP}$ and control groups in Caucasians [14].

Considering the influence of disease severity on polymorphism, we also performed stratified analysis by severity of CP. Pooled ORs revealed that no significant association existed between $M M P-1-16071 \mathrm{G} / 2 \mathrm{G}$ polymorphism and the risk of mild to moderate or severe CP in both Caucasians and Asians under all comparison models (Table 3). Besides, a study by Pirhan et al. [26] reported that the $-519 \mathrm{G}$ allele carrying genotypes of $M M P-1$ gene was not suggested to be related with severe $\mathrm{CP}$ in Caucasian population (adjusted $\mathrm{OR}=1.25, p=0.83$ ). With smoking being one of the major contributing factors in the susceptibility of periodontitis, we also performed subgroup analysis according to the smoking habit of subjects. In Caucasians, our results revealed that when only nonsmoking or smoking subjects were included, the difference between MMP-1 -1607 1G/2G polymorphism in $\mathrm{CP}$ patients and control population was not significant under all comparison models (Table 3). Likewise, apparent association could not be related with the stratified analysis by individual smoking habit in the allelic and genotype frequencies of MMP-1 -519 A/G polymorphism between CP and control groups in Caucasian population [14]. On the contrary, the results by Holla et al. [14] also suggested that there were significant differences in the distribution of $M M P$ $1-422 \mathrm{~A} / \mathrm{T}$ variant between a subgroup of smoking $\mathrm{CP}$ patients versus smoking controls in Caucasians $(p=0.017)$. 


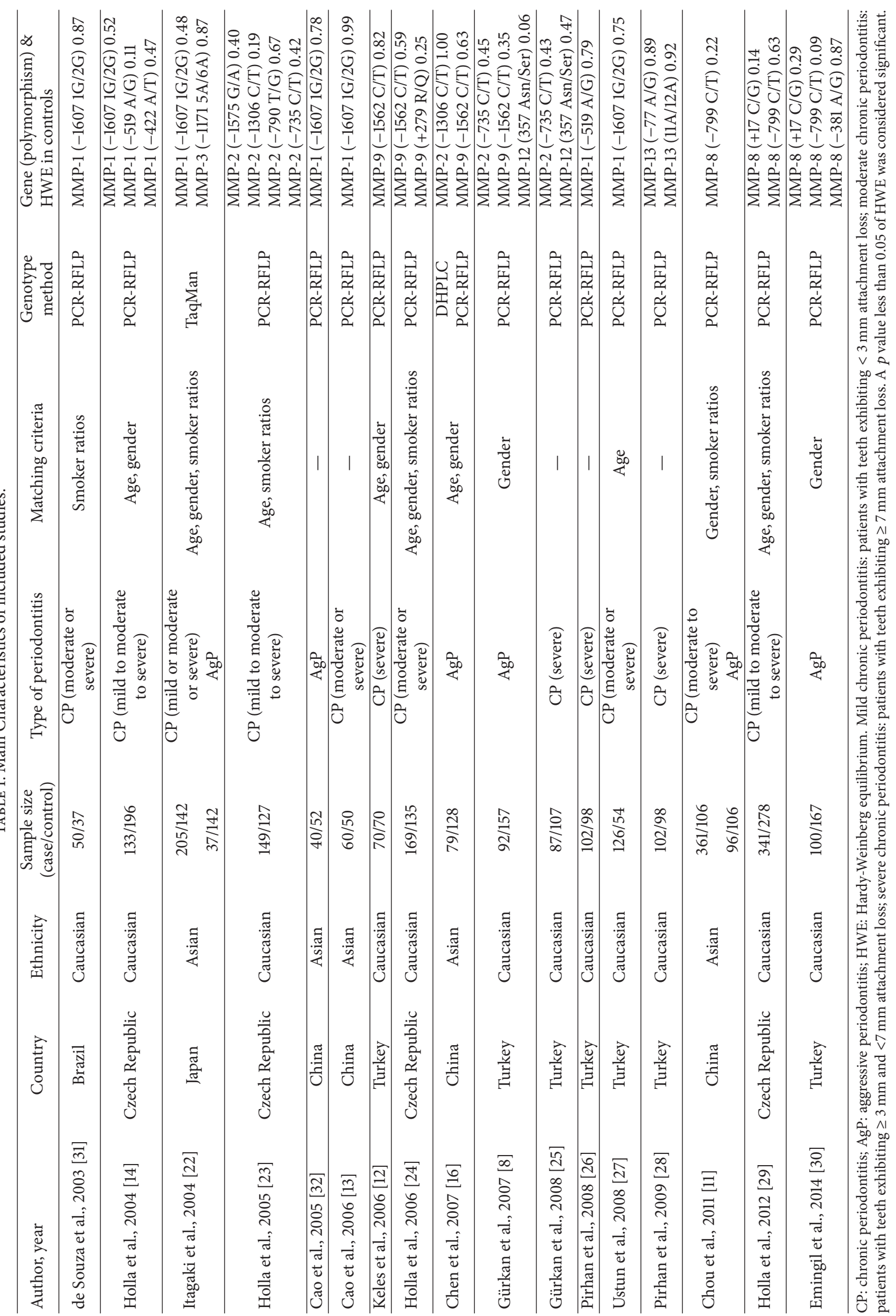


TABLE 2: Assessing the quality of included studies.

\begin{tabular}{|c|c|c|c|c|c|c|c|c|c|c|}
\hline \multirow{2}{*}{$\begin{array}{l}\text { Author, year } \\
\text { de Souza et al., } 2003 \text { [31] }\end{array}$} & \multicolumn{4}{|c|}{ Selection } & \multicolumn{2}{|c|}{ Comparability } & \multicolumn{3}{|c|}{ Exposure } & \multirow{2}{*}{$\begin{array}{c}\text { Score } \\
5\end{array}$} \\
\hline & ts & & & th & ț & & ts & 访 & & \\
\hline Holla et al., 2004 [14] & is & & is & ts & ts & is & is & is & & 7 \\
\hline Itagaki et al., 2004 [22] & is & & & t心 & t心 & is & ts & is & & 6 \\
\hline Holla et al., 2005 [23] & ts & & is & t & t & is & $\hbar$ & ts & & 7 \\
\hline Cao et al., 2005 [32] & is & & & is & is & & is & is & & 5 \\
\hline Cao et al., 2006 [13] & is & & & ts & ts & & 实 & is & & 5 \\
\hline Keles et al., 2006 [12] & t3 & 放 & is & t & t & & is & is & & 7 \\
\hline Holla et al., 2006 [24] & is & is & is & ¿ & ¿ & is & 站岤 & is & & 9 \\
\hline Chen et al., 2007 [16] & 头 & & is & 头 & 头 & is & istis & 论 & & 8 \\
\hline Gürkan et al., 2007 [8] & ts & is & & ts & ts & & 论㐾 & is & & 7 \\
\hline Gürkan et al., 2008 [25] & ts & is & & ts & ts & & 论证 & is & & 7 \\
\hline Pirhan et al., 2008 [26] & ts & is & & ts & ts & is & is & is & ts & 8 \\
\hline Ustun et al., 2008 [27] & is & & & ¿ & ¿ & & is & is & & 5 \\
\hline Pirhan et al., 2009 [28] & ts & is & & it & ts & & 他场 & is & & 7 \\
\hline Chou et al., 2011 [11] & ts & is & & ts & ts & is & is & is & & 7 \\
\hline Holla et al., 2012 [29] & is & is & is & is & ts & is & is & ts & & 8 \\
\hline Emingil et al., 2014 [30] & it & is & & is & 头 & is & is & is & & 7 \\
\hline
\end{tabular}

(1) Is the case definition adequate?

(a) Yes, with independent validation is

(b) Yes, for example, record linkage or based on self-reports

(c) No description

(2) Representativeness of the cases

(a) Consecutive or obviously representative series of cases $i$

Selection

(b) Potential for selection biases or not stated

(3) Selection of controls

(a) Community controls is

(b) Hospital controls

(c) No description

(4) Definition of controls

(a) No history of disease (endpoint) is

(b) No description of source

(1) Comparability of cases and controls on the basis of the design or analysis

Comparability

Exposure (a) Study controls for the most important factor (HWE in control group) is
(b) Study controls for any additional factor (e.g., age, gender, and smoker ratios) is

(1) Ascertainment of exposure

(a) Secure record is

(b) Structured interview where blind to case/control status is

(c) Interview not blinded to case/control status

(d) Written self-report or medical record only

(e) No description

(2) Same method of ascertainment for cases and controls

(a) Yes $i s$

(b) No

(3) Nonresponse rate

(a) Same rate for both groups $\downarrow$

(b) Nonrespondents described

(c) Rate different and no designation 


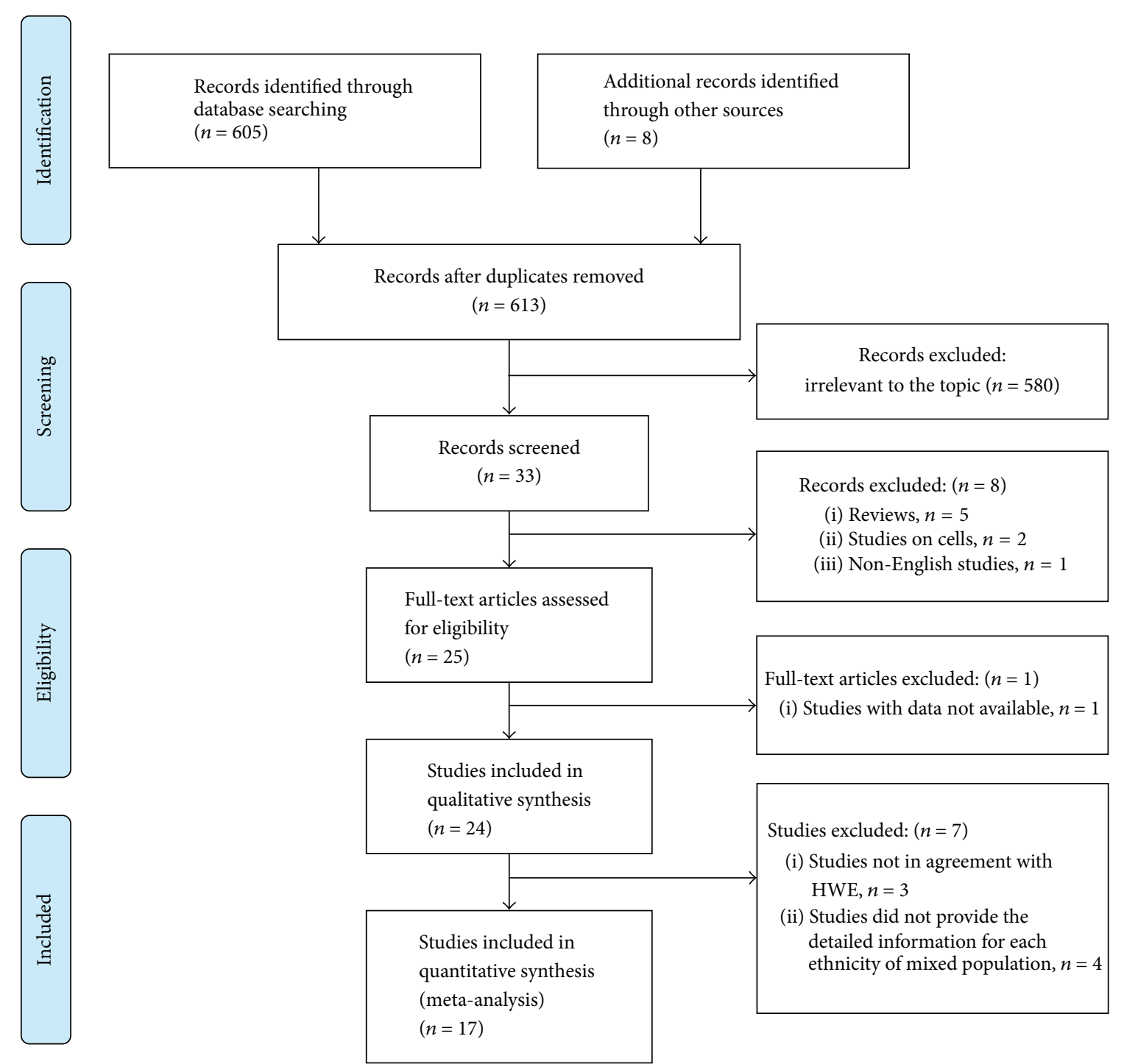

FIgURE 1: Flow of study identification, inclusion, and exclusion.

3.2. $M M P-2$. In the present meta-analysis, we failed to associate $M M P-2-735 \mathrm{C} / \mathrm{T}$ polymorphism with $\mathrm{CP}$ risk in Caucasian population under all comparison models (Table 3; Figure 2). Besides, a study by Gürkan et al. [8] revealed that this SNP was also not related to AgP risk in Caucasians. Similarly, no significant association of MMP-2 -1575 G/A, -1306 C/T, and $-790 \mathrm{~T} / \mathrm{G}$ SNPs with the susceptibility to periodontitis was observed in Caucasian and Asian populations [16, 23].

As far as the severity of CP was considered, the allelic and genotype distributions of $M M P-2-735 \mathrm{C} / \mathrm{T}$ variant were similar in severe $\mathrm{CP}$ and healthy subjects in Caucasians [25]. When stratified by smoking habit, we found that this polymorphism was not linked with the risk of CP in nonsmoking Caucasian patients and controls without smoking history under all comparison models (Table 3). Likewise, the results of subgroup analysis by Gürkan et al. [8] showed that there was no significant difference regarding the distribution of this SNP between nonsmoking $\mathrm{AgP}$ and nonsmoking healthy subjects in Caucasian population. Besides, a similar distribution of other three $M M P-2$ variants was also observed between CP patients and controls in subgroup analysis according to smoking status in Caucasians [23].

3.3. MMP-9. Our meta-analysis results revealed that $M M P-9$ $-1562 \mathrm{C} / \mathrm{T}$ SNP might not contribute to CP risk in Caucasians under all comparison models (Table 3; Figure 2). Likewise, the results by Chen et al. [16] and Gürkan et al. [8] failed to find a significant association of this variant with the risk of AgP in Asian and Caucasian populations, respectively. Besides, any significant association of $M M P-9+279 \mathrm{R} / \mathrm{Q}$ polymorphism with the susceptibility to $\mathrm{CP}$ was also absent in Caucasians [24].

When stratified by the severity of CP, pooled ORs also did not reveal any significant association between MMP-9 $-1562 \mathrm{C} / \mathrm{T}$ variant and severe CP risk in Caucasians under all comparison models (Table 3). Similarly, it was reported by 


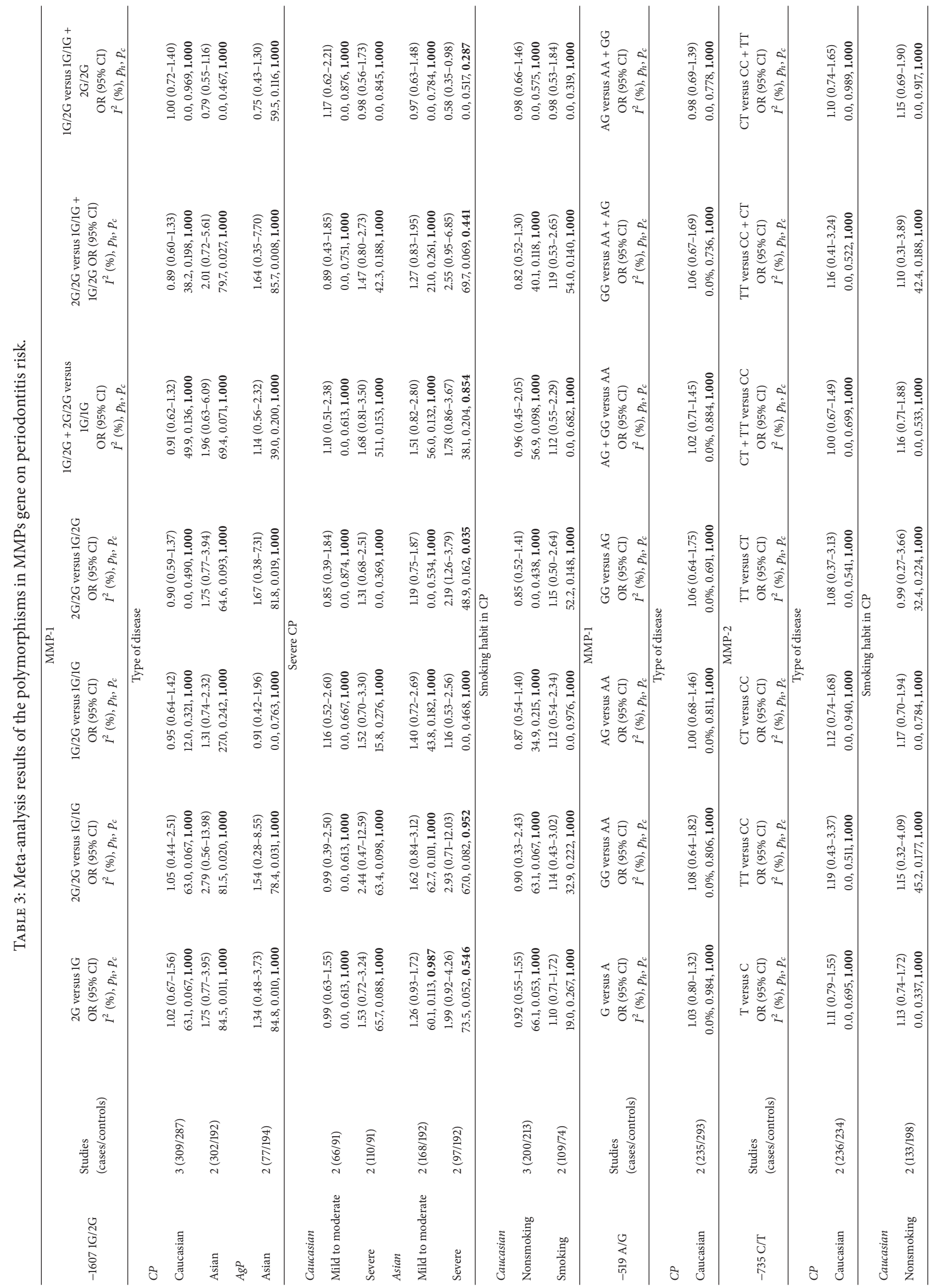




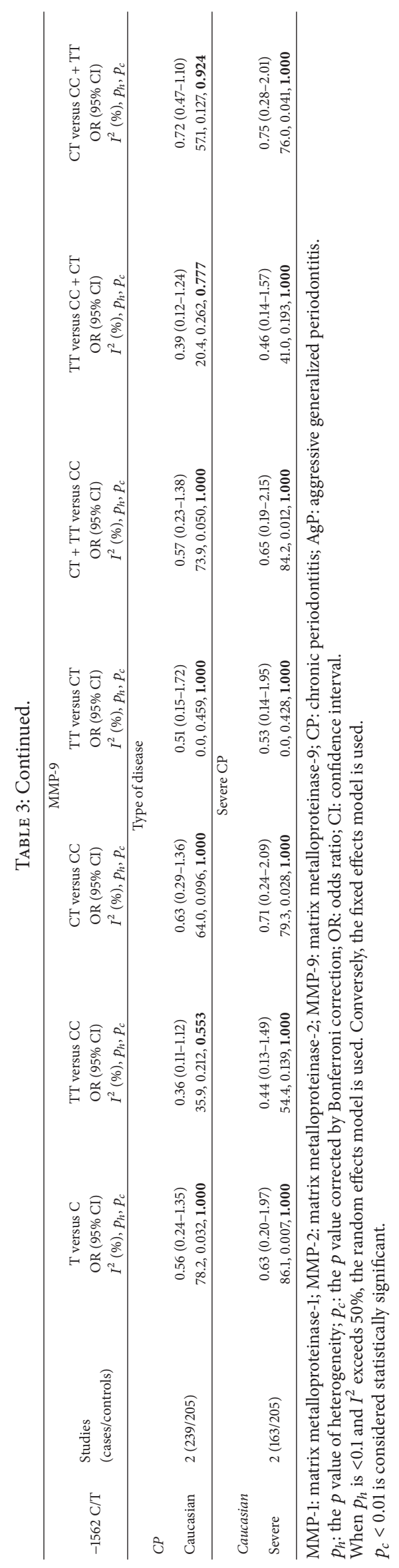




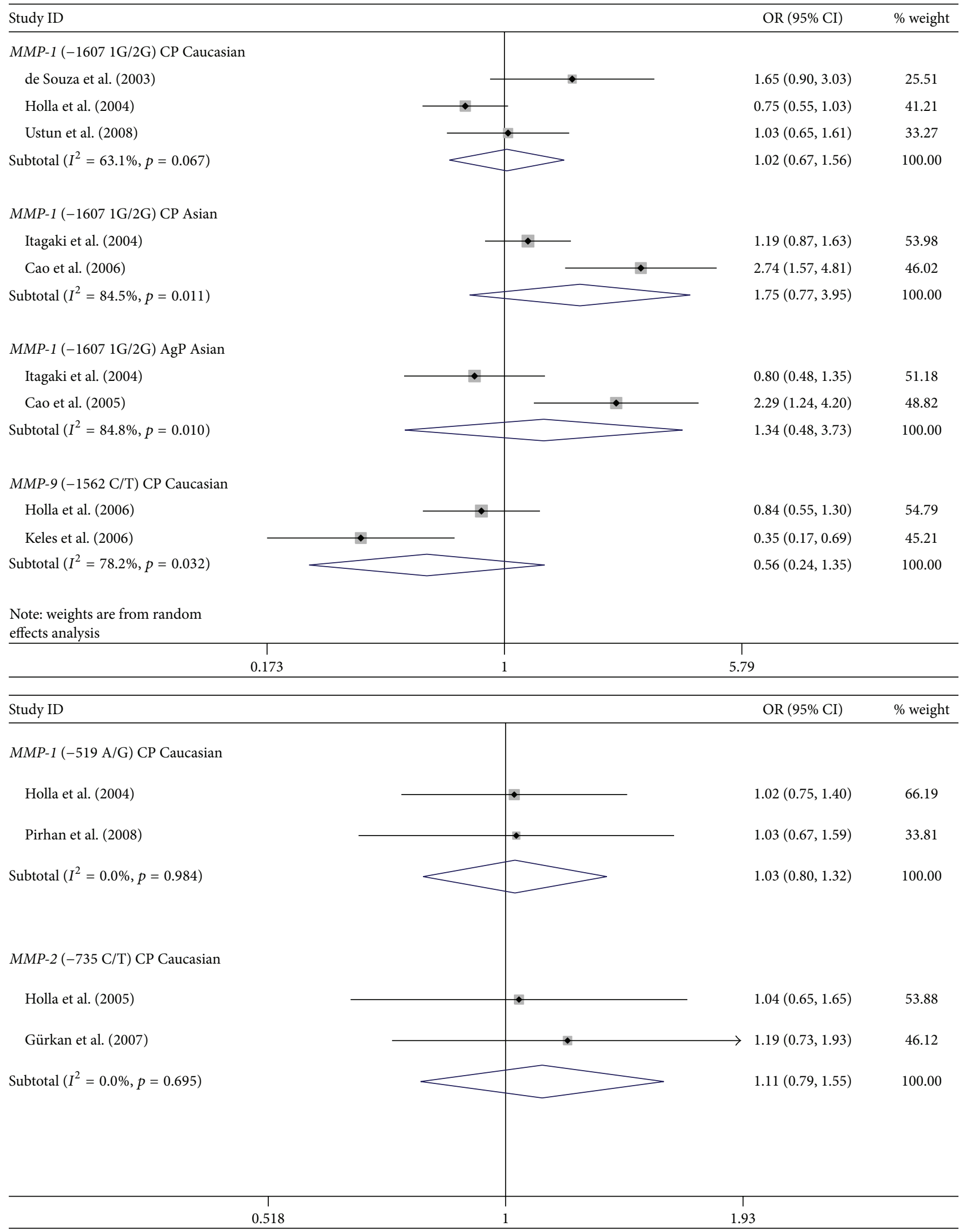

(a) Mutant allele versus wild allele

Figure 2: Continued. 


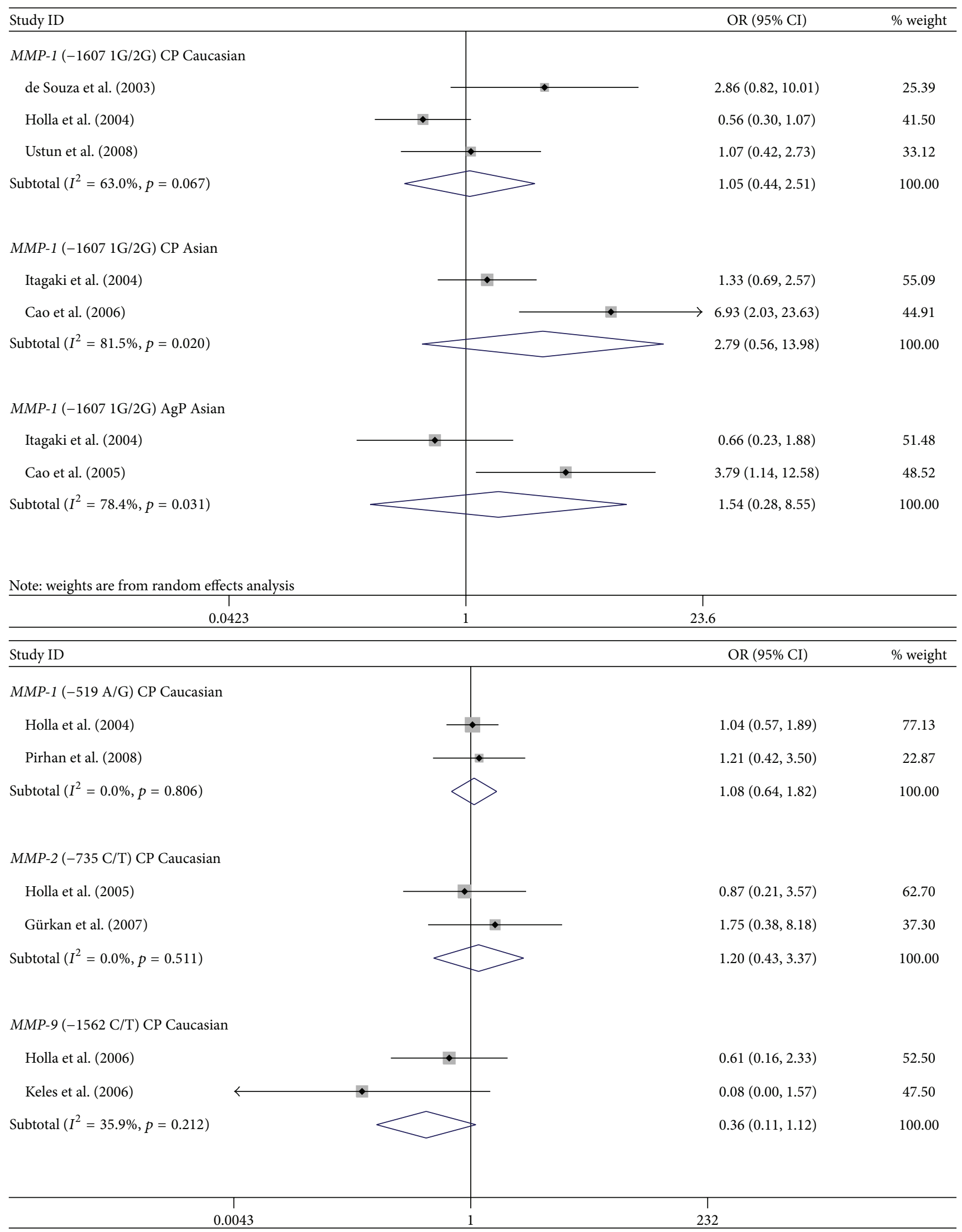

(b) Homozygous rare versus homozygous frequent

Figure 2: Continued. 


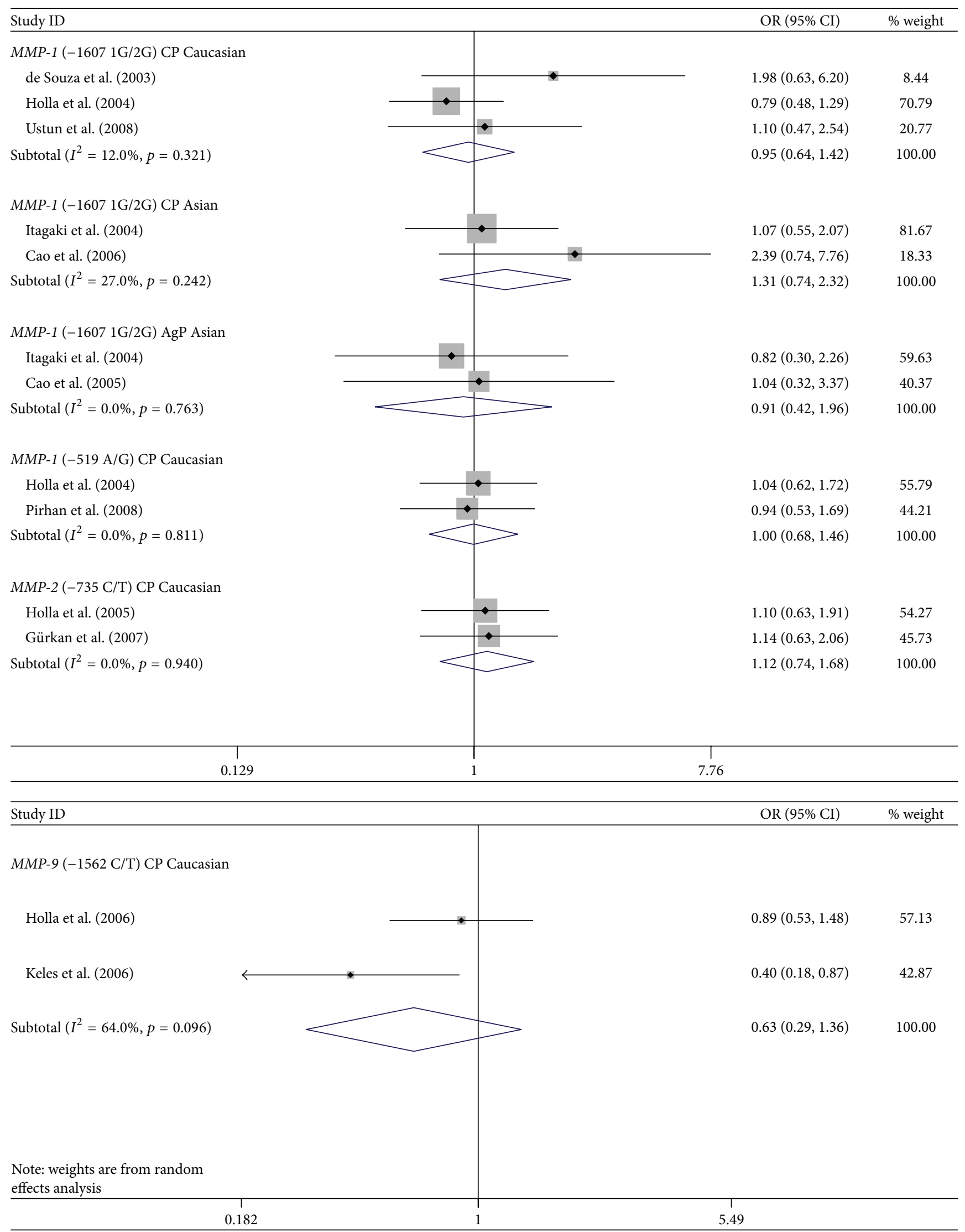

(c) Heterozygous versus homozygous frequent

FIgure 2: Continued. 


\begin{tabular}{|c|c|c|c|c|}
\hline Study ID & & & OR $(95 \% \mathrm{CI})$ & $\%$ weight \\
\hline \multicolumn{5}{|l|}{ MMP-1 (-1607 1G/2G) CP Caucasian } \\
\hline de Souza et al. (2003) & & $\longrightarrow$ & $1.44(0.53,3.93)$ & 14.26 \\
\hline Holla et al. (2004) & $\longrightarrow$ & - & $0.72(0.39,1.32)$ & 55.00 \\
\hline Ustun et al. (2008) & $i$ & & $0.98(0.46,2.06)$ & 30.74 \\
\hline Subtotal $\left(I^{2}=0.0 \%, p=0.490\right)$ & & & $0.90(0.59,1.37)$ & 100.00 \\
\hline \multicolumn{5}{|l|}{ MMP-1 (-519 A/G) CP Caucasian } \\
\hline Holla et al. (2004) & & & $1.00(0.57,1.77)$ & 80.46 \\
\hline Pirhan et al. (2008) & & $\rightarrow$ & $1.29(0.44,3.79)$ & 19.54 \\
\hline Subtotal $\left(I^{2}=0.0 \%, p=0.691\right)$ & & & $1.06(0.64,1.75)$ & 100.00 \\
\hline \multicolumn{5}{|l|}{ MMP-2 (-735 C/T) CP Caucasian } \\
\hline Holla et al. (2005) & $\rightarrow$ & & $0.79(0.18,3.42)$ & 61.29 \\
\hline Gürkan et al. (2007) & & $\bullet$ & $1.54(0.32,7.41)$ & 38.71 \\
\hline Subtotal $\left(I^{2}=0.0 \%, p=0.541\right)$ & & & $1.08(0.37,3.13)$ & 100.00 \\
\hline \multicolumn{5}{|l|}{ MMP-9 (-1562 C/T) CP Caucasian } \\
\hline Holla et al. (2006) & $\longrightarrow$ & & $0.69(0.17,2.75)$ & 63.10 \\
\hline Keles et al. (2006) & $\longrightarrow$ & & $0.20(0.01,4.04)$ & 36.90 \\
\hline Subtotal $\left(I^{2}=0.0 \%, p=0.459\right)$ & & $>$ & $0.51(0.15,1.72)$ & 100.00 \\
\hline $\begin{array}{c} \\
0.0101 \\
\end{array}$ & 1 & $\begin{array}{c}1 \\
99.2 \\
\end{array}$ & & \\
\hline Study ID & & & OR $(95 \% \mathrm{CI})$ & $\%$ weight \\
\hline \multicolumn{5}{|l|}{$M M P-1(-1607$ 1G/2G) CP Asian } \\
\hline Itagaki et al. (2004) & & $\longrightarrow$ & $1.24(0.78,1.97)$ & 59.94 \\
\hline Cao et al. (2006) & & & $2.90(1.21,6.93)$ & 40.06 \\
\hline Subtotal $\left(I^{2}=64.6 \%, p=0.093\right)$ & & & $1.75(0.77,3.94)$ & 100.00 \\
\hline \multicolumn{5}{|l|}{ MMP-1 (-1607 1G/2G) AgP Asian } \\
\hline Itagaki et al. (2004) & $\rightarrow$ & & $0.80(0.36,1.80)$ & 51.67 \\
\hline Cao et al. (2005) & & $\longrightarrow$ & $3.63(1.38,9.59)$ & 48.33 \\
\hline Subtotal $\left(I^{2}=81.8 \%, p=0.019\right)$ & & $=$ & $1.67(0.38,7.31)$ & 100.00 \\
\hline \multicolumn{5}{|l|}{ Note: weights are from random effects analysis } \\
\hline $\begin{array}{c} \\
\\
0.104\end{array}$ & 1 & $\begin{array}{c}1 \\
9.59\end{array}$ & & \\
\hline
\end{tabular}

(d) Homozygous rare versus heterozygous

Figure 2: Continued. 


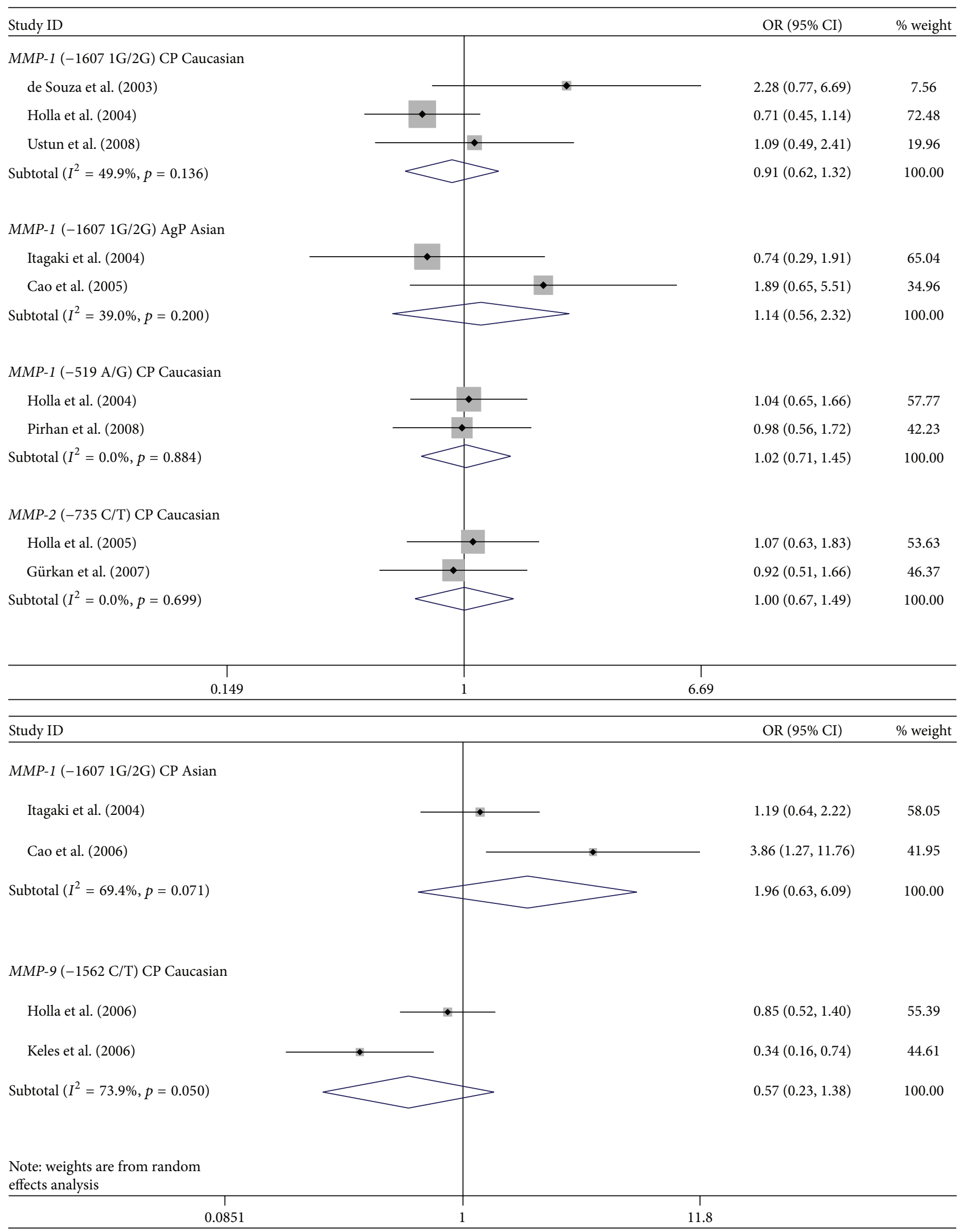

(e) Heterozygous + homozygous rare versus homozygous frequent

Figure 2: Continued. 


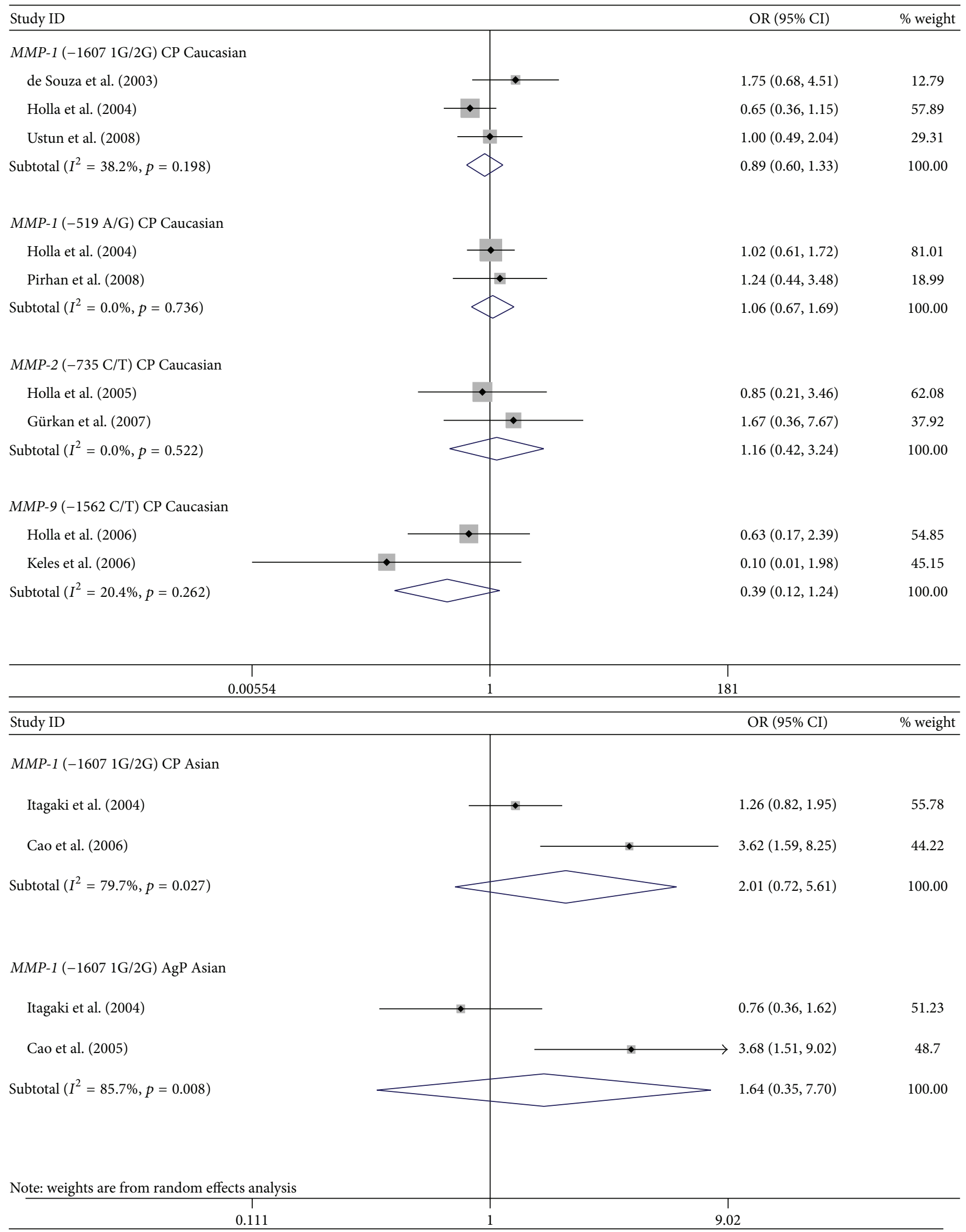

(f) Homozygous rare versus heterozygous + homozygous frequent

Figure 2: Continued. 


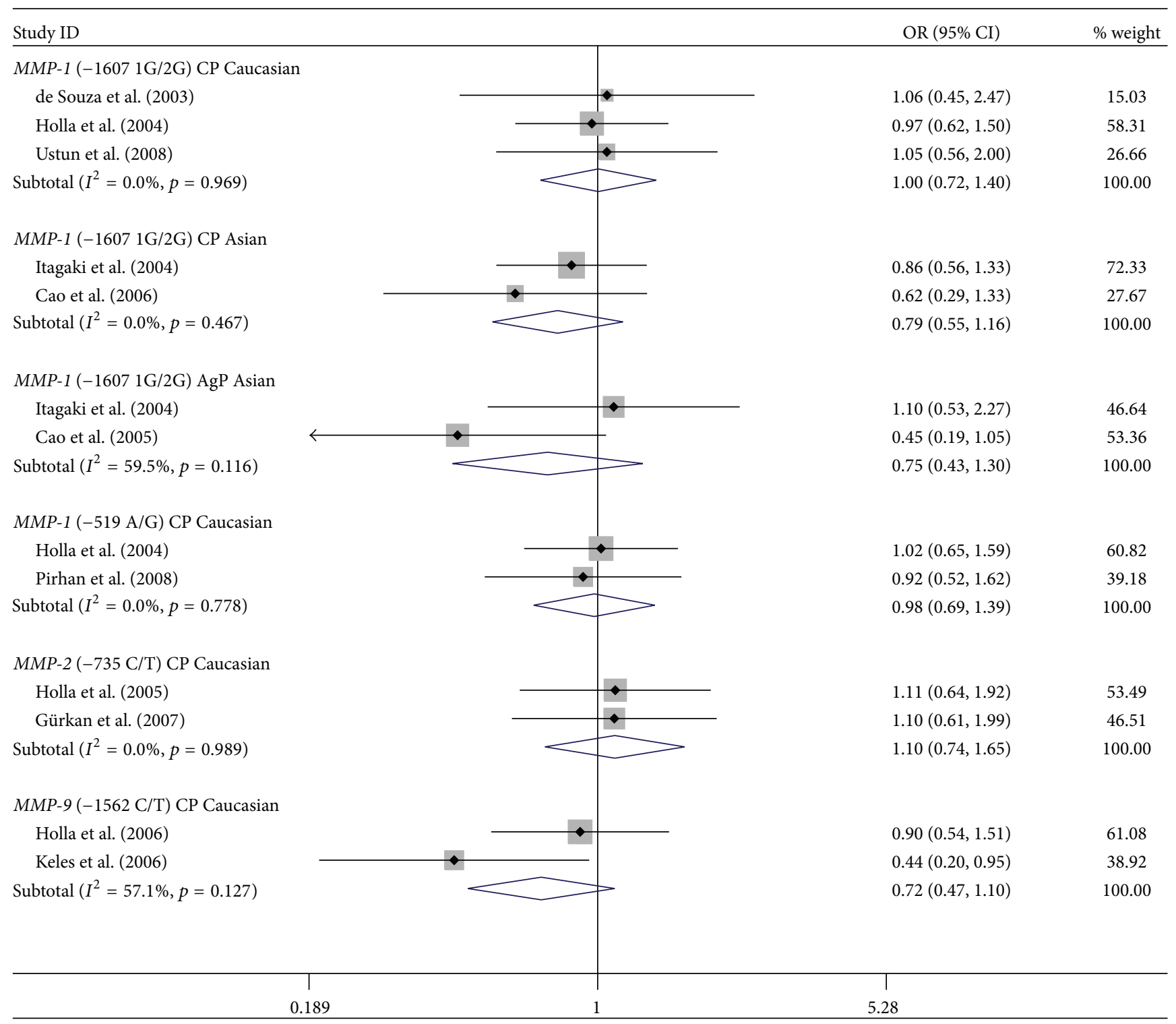

(g) Heterozygous versus homozygous frequent + homozygous rare

FIGURE 2: Forest plot of periodontitis risk associated with MMPs polymorphisms under all comparison models.

Holla et al. [24] that there was no difference in the distribution of $M M P-9+279$ R/Q SNP between the Caucasian CP patients with mild to moderate disease and those with severe disease. Concerning the smoking habit of subjects, the results by Holla et al. [24] suggested no significant difference in the allele and genotype frequencies of MMP-9 -1562 C/T polymorphism between smoking or nonsmoking $\mathrm{CP}$ patients and controls with or without smoking history in Caucasians. Moreover, when the smokers were excluded, the distribution of this SNP in the nonsmoking Caucasian subjects with AgP was similar to that in the healthy group [8].

3.4. Other MMPs. One SNP, $-11715 \mathrm{~A} / 6 \mathrm{~A}$ (in the promoter region of $M M P-3$ gene), has been investigated. In the study by Itagaki et al. [22], they failed to support the influence of this polymorphism on susceptibility to both CP $(p=0.935)$ and $\operatorname{AgP}(p=0.057)$ in Asians. Moreover, as far as the severity of CP was concerned, the results by Itagaki et al. [22] also revealed that in Asian population, there were no statistically significant differences in the distribution of this variant among three CP phenotypes (severe, moderate, and slight) $(p=0.240,0.188$, and 0.114 , resp.).

Variation in $M M P-8$ gene, particularly of $-799 \mathrm{C} / \mathrm{T},-381$ $\mathrm{A} / \mathrm{G}$, and $+17 \mathrm{C} / \mathrm{G}$ SNPs, has been investigated in association with periodontitis. As for $M M P-8-799 \mathrm{C} / \mathrm{T}$ polymorphism, analysis of genotypes in periodontitis and healthy control groups in the study by Chou et al. [11] showed that the $-799 \mathrm{~T}$ allele was associated with increased risk of both AgP (adjusted OR $=1.99, p=0.04$ ) and CP (adjusted OR = 1.93, $p=0.007)$ in Asians. Likewise, Emingil et al. [30] has 
also found analogous results for the association between this variant and AgP risk $(p<0.005)$ in Caucasians. On the contrary, the results by Holla et al. [29] suggested no differences in the allelic and genotype frequencies of this SNP between Caucasian CP patients and controls $(p>0.05)$. Besides, as for $M M P-8-381 \mathrm{~A} / \mathrm{G}$ and $+17 \mathrm{C} / \mathrm{G}$ polymorphisms, studies conducted by Holla et al. [29] and Emingil et al. [30] revealed that there was no significant association of these two SNPs with the susceptibility to periodontitis in Caucasians. When stratified by smoking habit, a significant difference in $\mathrm{T}$ allele carriers of $M M P-8-799 \mathrm{C} / \mathrm{T}$ polymorphism in both AgP (adjusted OR $=2.33, p<0.05$ ) and $\mathrm{CP}$ (adjusted OR = 1.84, $p<0.05$ ) groups versus control group was found in nonsmokers subgroup analysis in Asian population [11], while studies by Holla et al. [29] and Emingil et al. [30] showed no association of all these three $M M P-8$ variants with the risk of $\mathrm{CP}$ and $\mathrm{AgP}$ in Caucasians when the group of subjects was divided according to smoking status.

A few articles have reported the relation of MMP-12-357 Asn/Ser as well as MMP-13 -77 A/G and 11A/12A SNPs to periodontitis risk in Caucasian population. In the studies by Gürkan et al. $[8,25]$, they could not succeed in establishing the relationship of MMP-12 -357 Asn/Ser variant with the susceptibility either to $\mathrm{AgP}(\mathrm{OR}=1.29,95 \% \mathrm{CI}=0.64-2.61$; $p=0.47)$ or to severe $\mathrm{CP}(\mathrm{OR}=0.80,95 \% \mathrm{CI}=0.31-2.03$; $p=0.56)$. Similarly, a study conducted by Pirhan et al. [28] also failed to reveal any significant influence regarding the distribution of $M M P-13-77 \mathrm{~A} / \mathrm{G}(\mathrm{OR}=0.11,95 \% \mathrm{CI}=$ $0.01-1.59 ; p=0.11$ ) and $11 \mathrm{~A} / 12 \mathrm{~A}$ (data not shown, $p>$ 0.05 ) polymorphisms on severe CP risk. Furthermore, in the nonsmoker subgroup analysis, the allelic and genotype frequencies of MMP-12-357 Asn/Ser variant in the nonsmoking subjects with AgP or CP was similar to those in the healthy group according to studies by Gürkan et al. $[8,25]$.

3.5. Publication Bias and Sensitivity Analysis. The results of these two analyses are shown in Appendices S2 and S3.

\section{Discussion}

MMP-1 -1607 1G/2G, located on 11q22-q23 chromosome, is one of the most studied SNPs in periodontitis. Evidence from previous studies revealed that individuals carrying 2G/2G genotype appeared to be at greater risk for developing periodontitis than individuals who had $1 \mathrm{G} / 1 \mathrm{G}$ and $1 \mathrm{G} / 2 \mathrm{G}$ genotypes $[26,32]$. Although the exact mechanism behind these findings is not known, it has reported that the presence of $2 \mathrm{G}$ allele together with an adjacent adenosine creates a core binding site $\left(5^{\prime}-\mathrm{GGA}-3^{\prime}\right)$, which is the consensus sequence for the Ets family of transcription factors immediately adjacent to an AP-1 site [33]. Moreover, carriage of $2 \mathrm{G}$ allele is also shown to augment transcriptional activity by 37 -fold and may potentially increase the levels of protein expression [34]. This mechanism provides the molecular bases for a more intense degradation of periodontal extracellular matrix, leading to increased risk of periodontitis.

However, in our study we could not only find any significant association between MMP-1 -1607 1G/2G polymorphism and periodontitis risk, but also failed to associate
MMP-1 -519 A/G and -422 A/T SNPs with the susceptibility to periodontitis. Several reasons may contribute to our results. First, an overview of clinical outcomes revealed that, even with the same genotype, the presence of a high variation in MMP-1 expression among periodontitis individuals could be due to additional influence of specific periodontopathogens and cytokine stimulation [35]. Based on the results of these studies, a stronger signaling because of intense and sustained stimulation of host cells by periodontopathogens and by the inflammatory mediators (such as IL-1b and TNF-a) characteristically induced by them may overcome the genetic predisposition, and high levels of $M M P-1$ are transcribed irrespective of these SNPs [36].

Also, it is believed that the combination of several significant gene variants in certain individuals synergistically elevate the susceptibility to disease [37]. Since role of TIMPs in MMPs function cannot be denied, it can also be postulated that mutation of the position 2 (Thr in TIMP-1) greatly affects the affinity of TIMPs for MMPs and substitution to glycine essentially inactivates TIMP-1 for MMPs inhibition [38], thus potentiating MMPs activity. Besides, results of the linkage disequilibrium and the haplotype frequencies of $M M P-1$ and $M M P-3$ variants, both of which are located in $11 q 22.3$ chromosome near to each other, indicated that the risk 2G allele in $M M P-1$ was more frequently linked to the nonrisk 6A allele in $M M P-3$, suggesting that the risk and nonrisk linkage combination might lead to the functional compensation of MMP function, to put it in another way, protective function of host homeostasis [22].

Furthermore, previous studies have hypothesized that covariates like severity of the disease and smoking may contribute towards regulation of MMP-1 expression in diseased periodontium [39]. So, we also performed subgroup analyses according to severity of CP and smoking habit of subjects. Similarly, lack of association between $M M P-1$ gene variants in terms of CP severity as well as smoking status and periodontitis risk was observed in the present meta-analysis and systematic review. All these above results may lead to the conclusion that an increase in mRNA transcription caused by these $M M P-1$ promoter SNPs may not necessarily lead to an increased effect of MMP-1 on the extracellular matrix of periodontal tissues, and many other factors such as bacterial metabolites, cytokines, and other gene variants are supposed to be involved in the regulation of MMP-1 expression and functionality.

The $M M P-2-735 \mathrm{C} / \mathrm{T}$ polymorphism is a synonymous mutation, resulting in the same amino acid (threonine) at codon 460 regardless of the allele present. It has been shown that variation of this SNP at synonymous sites could lead to allele-specific structural differences in mRNA that could affect mRNA structure dependent mechanisms [40], which could have functional consequences of increased MMP-2 expression. In oral cancer, previous studies have verified that patients with MMP-2 -735 CC genotype present increased risk for developing oral squamous cell carcinoma when compared to those with CT or TT genotype [41]. These findings were consistent with other studies that have linked this genotype with an increased risk of development of lung cancer [42], gastric cardia adenocarcinoma [43], 
and abdominal aortic aneurysm [44], suggesting that this polymorphism is identified as a promising candidate for neoplasms.

On the contrary, several studies failed to show association between this variant and the susceptibility to periodontitis [8, $23,25]$. Likewise, our results also found no association of this SNP with the risk of both CP and AgP, so did MMP-2 -1575 G/A and $-1306 \mathrm{C} / \mathrm{T}$, as well as $-790 \mathrm{~T} / \mathrm{G}$ SNPs. A possible explanation would be that the rare allele of these variants could disrupt a Sp-1 binding site within the promoter region of $M M P-2$ gene, thus leading to lower $M M P-2$ promoter activity [45], which might also contribute towards negative association of these MMP-2 polymorphisms with periodontitis risk. Besides, when stratified by the severity of $\mathrm{CP}$ and smoking, a similar distribution of all these MMP-2 variants was observed between periodontitis patients and controls. So, we can make a conclusion that genetically determined mechanisms may not be important in tuning the effect of MMP-2 on periodontal tissues.

MMP-9-1562 C/T SNP, located on 20q11.2-q13.1 chromosome, has been under investigation for its association with an increased risk for the development of cancer and emphysema as well as many other diseases [46]. Based on the evidence of previous studies, the suggested mechanism behind a positive association of this polymorphism with disease risk might be that the MMP-9 expression is primarily controlled at the transcriptional level, where the promoter of MMP-9 gene responds to stimuli of various cytokines and growth factors [47]. Furthermore, the $\mathrm{T}$ allele of this variant can abolish a binding site for a transcription repressor and, thus, change the promoter activity of $M M P-9$, leading to increased MMP9 expression. Besides, an exchange of C-to-T at position -1562 can also alter the binding of a nuclear protein to this region, resulting in increased transcriptional activity in macrophages [48].

However, the present study failed to find any association of both MMP-9 - $1562 \mathrm{C} / \mathrm{T}$ and +279 R/Q SNPs with periodontitis risk. A possible explanation for this discrepancy may be that not only the variant, but several binding sites and also their length-dependent interaction with nuclear proteins may influence the transcriptional activity of the gene due to its close localization to the transcriptional start site [49]. In addition, recent evidence indicates that, in periodontitis, changes in MMP/TIMP balance occur as a result of physiological ageing and that gender might be a significant factor modifying this balance [50]. Although multiple genetic factors, including SNPs, are involved in pro- and antiinflammatory situations, effect of other factors like oxidantantioxidant imbalance and tissue remodeling cannot be denied and should be simultaneously considered to understand the entire picture of periodontitis risk.

The $-11715 \mathrm{~A} / 6 \mathrm{~A}$ variant, a well-characterized insertion/deletion polymorphism in the promoter region of $M M P$ 3 gene, is considered to be functionally involved in the process of periodontitis. The $5 \mathrm{~A}$ allele of this polymorphism has been shown to result in higher MMP-3 expression and enzyme activity, thereby increasing extracellular matrix breakdown because of disruption of a binding site for a nuclear factor kappa B, which acts as a transcriptional repressor [51].
Moreover, some studies reported positive association of this SNP with periodontitis and concluded that individuals with the $5 \mathrm{~A} / 5 \mathrm{~A}$ genotype were $2-3$ times more likely to develop periodontitis [15, 19]. Conversely, several other studies showed a nonsignificant trend for association of this variant with periodontitis, suggesting a likely attempt of the host environment to contain and perhaps specifically outbalance the increased MMP-3 levels to minimize tissue damage $[7,22]$.

Recently, several studies have investigated MMP-8 -799 $\mathrm{C} / \mathrm{T},-381 \mathrm{~A} / \mathrm{G}$, and $+17 \mathrm{C} / \mathrm{G}$ variants in different periodontal diseases. However, a significant correlation with periodontitis risk was only found in $M M P-8-799 \mathrm{C} / \mathrm{T}$ polymorphism, and it has been reported that $\mathrm{T}$ allele carriers have more MMP8 production in the periodontal environment with bacterial challenge compared to non-T allele carriers [30]. The exact mechanism behind this association is still unknown, but $\mathrm{T}$ allele of this variant has been proved to have about 1.8fold higher promoter activity than the $C$ allele [52]. Besides, MMP-8 activity has also been found to be modified in various organs and body fluids in smokers $[53,54]$, and tobaccoinduced degranulation events in neutrophils and increase in proinflammatory mediator burden can influence the expression level of MMP-8 in smokers' periodontal environment [55]. However, none of the previous studies have succeed in associating these $M M P-8$ variants with smoking and periodontitis risk, indicating smoking status may not exert an effect on the association of these SNPs with periodontitis susceptibility.

MMP-12 -357 Asn/Ser as well as MMP-13 -77 A/G and 11A/12A SNPs, located on 11q22.2-q22.3 chromosomes, has been evaluated with the periodontitis risk in a limited number of studies. And it is suggested that all these polymorphisms do not appear to have a significant influence on the susceptibility to periodontitis and are also not associated with the clinical severity of periodontitis as well as outcome of periodontal therapy and gingival crevicular fluid MMP-12/-13 levels [28]. Moreover, recent studies have also revealed that $M M P-2, M M P-3, M M P-7, M M P-8, M M P-11$, or $M M P-12$ single gene knockout mice failed to show any apparent disorders, suggesting that a single SNP of MMP might not contribute enough in the susceptibility or progression of a disease. A likely explanation for this behavior would be the sharing of common extracellular matrix substrates by some MMP members which might even compensate these functions for each other [56]. Furthermore, lack of association between these variants and periodontitis may also suggest that an increase in the MMP-12 or MMP-13 transcriptions may not necessarily lead to an increase in the destructive effect of these enzymes on the periodontal tissues.

When compared with previous similar meta-analysis and systematic reviews $[57,58]$, the present study has several strengths. First, almost all of these prior studies pooled ORs by using the data of trials investigating the mixed population; however, a meta-analysis of mixed ethnicities is meaningless for a genetic association study, owing to high population heterogeneity. As a result, we excluded the trials if they did not provide the detailed information for each ethnicity of a mixed population; moreover, in order to get more reliable results, all 
meta-analyses and subgroup analyses in our study were performed according to the racial descent. Besides, some of the previous meta-analyses even included studies in which genotype distributions of control subjects were varied from HWE; however, the allele-frequency comparison test is valid only if HWE conditions prevail. Therefore, in the current study, we also took into consideration this factor that might bias the results, suggesting that evidence from our meta-analysis should be considered to be convincing. Nevertheless, this study still has several potential limitations. One potential limitation is that our restriction on searching studies published in indexed journals and also studies published only in English could introduce an inherent bias for this analysis. Moreover, lack of information for the adjustments of major confounders including age, gender, and environmental factors might cause confounding bias so a more precise analysis would have been performed if all individual raw data had been available. Finally, there were only two ethnicity groups (Caucasian and Asian) included in the present study. Thus, it is doubtful whether the obtained conclusions were generalizable to other populations. Further studies on this topic in different ethnicities are expected to be conducted to strengthen our results.

In conclusion, the present meta-analysis and systematic review suggested that although studies of the association between MMP-8 -799 C/T variant and the susceptibility to periodontitis have not yielded consistent results, $M M P$ 1 (-1607 1G/2G, -519 A/G, and -422 A/T), MMP-2 (-1575 $\mathrm{G} / \mathrm{A},-1306 \mathrm{C} / \mathrm{T},-790 \mathrm{~T} / \mathrm{G}$, and $-735 \mathrm{C} / \mathrm{T}), \mathrm{MMP}-3(-1171$ 5A/6A), MMP-8 (-381 A/G and +17 C/G), MMP-9 (-1562 $\mathrm{C} / \mathrm{T}$ and $+279 \mathrm{R} / \mathrm{Q})$, and MMP-12 (-357 Asn/Ser), as well as $M M P-13(-77 \mathrm{~A} / \mathrm{G}$ and $11 \mathrm{~A} / 12 \mathrm{~A})$ SNPs are not related to periodontitis risk. However, further well-designed studies with larger sample size and more ethnic groups are required to validate the negative association identified in our study. Besides, we expect that in the future, analyses using polymorphisms will not only identify individual variations within disease comparisons but also help in identification of human response to various therapies. Consequently, even though significant insights have been gained into the role of MMPs and their function, a lot of work needs to be done before the roles of MMPs in development of periodontitis are fully elucidated.

\section{Disclosure}

The authors Ying Zhu and Pradeep Singh should be regarded as first joint authors.

\section{Competing Interests}

The authors declare that they have no competing interests.

\section{Authors' Contributions}

The authors Wenyang Li, Ying Zhu, and Pradeep Singh contributed equally to this study.

\section{References}

[1] F. O. Costa, A. N. Guimarães, L. O. M. Cota et al., "Impact of different periodontitis case definitions on periodontal research," Journal of oral science, vol. 51, no. 2, pp. 199-206, 2009.

[2] A. Endo, T. Watanabe, N. Ogata et al., "Comparative genome analysis and identification of competitive and cooperative interactions in a polymicrobial disease," ISME Journal, vol. 9, no. 3, pp. 629-642, 2015.

[3] U. M. Irfan, D. V. Dawson, and N. F. Bissada, "Epidemiology of periodontal disease: a review and clinical perspectives," Journal of the International Academy of Periodontology, vol. 3, no. 1, pp. $14-21,2001$.

[4] R. P. Verma and C. Hansch, "Matrix metalloproteinases (MMPs): chemical-biological functions and (Q)SARs," Bioorganic and Medicinal Chemistry, vol. 15, no. 6, pp. 2223-2268, 2007.

[5] J. L. Lauer-Fields, D. Juska, and G. B. Fields, "Matrix metalloproteinases and collagen catabolism," Biopolymers, vol. 66, no. 1, pp. 19-32, 2002.

[6] B. S. Sekhon, "Matrix metalloproteinases-an overview," Research and Reports in Biology, vol. 1, pp. 1-20, 2010.

[7] A. Letra, R. M. Silva, R. J. Rylands et al., "MMP3 and TIMP1 variants contribute to chronic periodontitis and may be implicated in disease progression," Journal of Clinical Periodontology, vol. 39, no. 8, pp. 707-716, 2012.

[8] A. Gürkan, G. Emingil, B. H. Saygan et al., "Matrix metalloproteinase-2, -9 , and -12 gene polymorphisms in generalized aggressive periodontitis," Journal of Periodontology, vol. 78, no. 12, pp. 2338-2347, 2007.

[9] V. Fontana, P. S. Silva, R. F. Gerlach, and J. E. Tanus-Santos, "Circulating matrix metalloproteinases and their inhibitors in hypertension," Clinica Chimica Acta, vol. 413, no. 7-8, pp. 656662, 2012.

[10] G. Li, Y. Yue, Y. Tian et al., "Association of matrix metalloproteinase (MMP)-1, 3, 9, interleukin (IL)-2, 8 and cyclooxygenase (COX)-2 gene polymorphisms with chronic periodontitis in a Chinese population," Cytokine, vol. 60, no. 2, pp. 552-560, 2012.

[11] Y.-H. Chou, Y.-P. Ho, Y.-C. Lin et al., "MMP-8 -799 C>T genetic polymorphism is associated with the susceptibility to chronic and aggressive periodontitis in Taiwanese," Journal of Clinical Periodontology, vol. 38, no. 12, pp. 1078-1084, 2011.

[12] G. C. Keles, S. Gunes, A. P. Sumer et al., "Association of matrix metalloproteinase-9 promoter gene polymorphism with chronic periodontitis," Journal of Periodontology, vol. 77, no. 9, pp. 1510-1514, 2006.

[13] Z. Cao, C. Li, and G. Zhu, "MMP-1 promoter gene polymorphism and susceptibility to chronic periodontitis in a Chinese population," Tissue Antigens, vol. 68, no. 1, pp. 38-43, 2006.

[14] L. I. Holla, M. Jurajda, A. Fassmann, N. Dvorakova, V. Znojil, and J. Vacha, "Genetic variations in the matrix metalloproteinase-1 promoter and risk of susceptibility and/or severity of chronic periodontitis in the Czech population," Journal of Clinical Periodontology, vol. 31, no. 8, pp. 685-690, 2004.

[15] C. M. Astolfi, A. L. Shinohara, R. A. da Silva, M. C. L. G. Santos, S. R. P. Line, and A. P. de Souza, "Genetic polymorphisms in the MMP-1 and MMP-3 gene may contribute to chronic periodontitis in a Brazilian population," Journal of Clinical Periodontology, vol. 33, no. 10, pp. 699-703, 2006.

[16] D. Chen, Q. Wang, Z.-W. Ma et al., "MMP-2, MMP-9andTIMP2gene polymorphisms in Chinese patients with generalized 
aggressive periodontitis," Journal of Clinical Periodontology, vol. 34, no. 5, pp. 384-389, 2007.

[17] S. M. Luczyszyn, C. M. De Souza, A. P. R. Braosi et al., "Analysis of the association of an MMP1 promoter polymorphism and transcript levels with chronic periodontitis and end-stage renal disease in a Brazilian population," Archives of Oral Biology, vol. 57, no. 7, pp. 954-963, 2012.

[18] C. E. Repeke, A. P. F. Trombone, S. B. Ferreira Jr. et al., "Strong and persistent microbial and inflammatory stimuli overcome the genetic predisposition to higher matrix metalloproteinase1 (MMP-1) expression: a mechanistic explanation for the lack of association of MMP1-1607 single-nucleotide polymorphism genotypes with MMP-1 expression in chronic periodontitis lesions," Journal of Clinical Periodontology, vol. 36, no. 9, pp. 726-738, 2009.

[19] W. T. Y. Loo, M. Wang, L. J. Jin, M. N. B. Cheung, and G. R. Li, "Association of matrix metalloproteinase (MMP-1, MMP-3 and MMP-9) and cyclooxygenase-2 gene polymorphisms and their proteins with chronic periodontitis," Archives of Oral Biology, vol. 56, no. 10, pp. 1081-1090, 2011.

[20] A. P. de Souza, P. C. Trevilatto, R. M. Scarel-Caminaga, R. B. de Brito Jr., S. P. Barros, and S. R. P. Line, "Analysis of the MMP9 (C-1562 T) and TIMP-2 (G-418C) gene promoter polymorphisms in patients with chronic periodontitis," Journal of Clinical Periodontology, vol. 32, no. 2, pp. 207-211, 2005.

[21] D. M. Isaza-Guzmán, C. Arias-Osorio, M. C. Martínez-Pabón, and S. I. Tobón-Arroyave, "Salivary levels of matrix metalloproteinase (MMP)-9 and tissue inhibitor of matrix metalloproteinase (TIMP)-1: a pilot study about the relationship with periodontal status and MMP-9-1562C/T gene promoter polymorphism," Archives of Oral Biology, vol. 56, no. 4, pp. 401411, 2011.

[22] M. Itagaki, T. Kubota, H. Tai et al., "Matrix metalloproteinase-1 and -3 gene promoter polymorphisms in Japanese patients with periodontitis," Journal of Clinical Periodontology, vol. 31, no. 9, pp. 764-769, 2004.

[23] L. I. Holla, A. Fassmann, A. Vasku et al., "Genetic variations in the human gelatinase A (matrix metalloproteinase-2) promoter are not associated with susceptibility to, and severity of, chronic periodontitis," Journal of Periodontology, vol. 76, no. 7, pp. 10561060, 2005.

[24] L. I. Holla, A. Fassmann, J. Mužik, J. Vanek, and A. Vasku, "Functional polymorphisms in the matrix metalloproteinase-9 gene in relation to severity of chronic periodontitis," Journal of Periodontology, vol. 77, no. 11, pp. 1850-1855, 2006.

[25] A. Gürkan, G. Emingil, B. H. Saygan et al., "Gene polymorphisms of matrix metalloproteinase-2, -9 and -12 in periodontal health and severe chronic periodontitis," Archives of Oral Biology, vol. 53, no. 4, pp. 337-345, 2008.

[26] D. Pirhan, G. Atilla, G. Emingil, T. Sorsa, T. Tervahartiala, and A. Berdeli, "Effect of MMP-1 promoter polymorphisms on GCF MMP-1 levels and outcome of periodontal therapy in patients with severe chronic periodontitis," Journal of Clinical Periodontology, vol. 35, no. 10, pp. 862-870, 2008.

[27] K. Ustun, N. Ö. Alptekin, S. S. Hakki, and E. E. Hakki, "Investigation of matrix metalloproteinase-1-1607 1G/2G polymorphism in a Turkish population with periodontitis," Journal of Clinical Periodontology, vol. 35, no. 12, pp. 1013-1019, 2008.

[28] D. Pirhan, G. Atilla, G. Emingil, T. Tervahartiala, T. Sorsa, and A. Berdeli, "MMP-13 promoter polymorphisms in patients with chronic periodontitis: effects on GCF MMP-13 levels and outcome of periodontal therapy," Journal of Clinical Periodontology, vol. 36, no. 6, pp. 474-481, 2009.

[29] L. I. Holla, B. Hrdlickova, J. Vokurka, and A. Fassmann, "Matrix metalloproteinase 8 (MMP8) gene polymorphisms in chronic periodontitis," Archives of Oral Biology, vol. 57, no. 2, pp. 188196, 2012.

[30] G. Emingil, B. Han, A. Gürkan et al., "Matrix metalloproteinase (MMP)-8 and tissue inhibitor of MMP-1 (TIMP-1) gene polymorphisms in generalized aggressive periodontitis: gingival crevicular fluid MMP-8 and TIMP-1 levels and outcome of periodontal therapy," Journal of Periodontology, vol. 85, no. 8, pp. 1070-1080, 2014.

[31] A. P. de Souza, P. C. Trevilatto, R. M. Scarel-Caminaga, R. B. Brito Jr., and S. R. P. Line, "MMP-1 promoter polymorphism: association with chronic periodontitis severity in a Brazilian population," Journal of Clinical Periodontology, vol. 30, no. 2, pp. 154-158, 2003.

[32] Z. Cao, C. Li, L. Jin, and E. F. Corbet, "Association of matrix metalloproteinase-1 promoter polymorphism with generalized aggressive periodontitis in a Chinese population," Journal of Periodontal Research, vol. 40, no. 6, pp. 427-431, 2005.

[33] J. L. Rutter, T. I. Mitchell, G. Butticè et al., "A single nucleotide polymorphism in the matrix metalloproteinase-1 promoter creates an Ets binding site and augments transcription," Cancer Research, vol. 58, no. 23, pp. 5321-5325, 1998.

[34] M. D. Sternlicht and Z. Werb, "How matrix metalloproteinases regulate cell behavior," Annual Review of Cell and Developmental Biology, vol. 17, pp. 463-516, 2001.

[35] A. Kasamatsu, K. Uzawa, K. Shimada et al., "Elevation of galectin- 9 as an inflammatory response in the periodontal ligament cells exposed to Porphylomonas gingivalis lipopolysaccharide in vitro and in vivo," International Journal of Biochemistry and Cell Biology, vol. 37, no. 2, pp. 397-408, 2005.

[36] C. Rossa Jr., L. Min, P. Bronson, and K. L. Kirkwood, “Transcriptional activation of MMP-13 by periodontal pathogenic LPS requires p38 MAP kinase," Journal of Endotoxin Research, vol. 13, no. 2, pp. 85-93, 2007.

[37] S. A. Dowsett, L. Archila, T. Foroud, D. Koller, G. J. Eckert, and M. J. Kowolik, "The effect of shared genetic and environmental factors on periodontal disease parameters in untreated adult siblings in Guatemala," Journal of Periodontology, vol. 73, no. 10, pp. 1160-1168, 2002.

[38] Q. Meng, V. Malinovskii, W. Huang et al., "Residue 2 of TIMP1 is a major determinant of affinity and specificity for matrix metalloproteinases but effects of substitutions do not correlate with those of the corresponding P1' residue of substrate," Journal of Biological Chemistry, vol. 274, no. 15, pp. 10184-10189, 1999.

[39] Y.-C. Chang, S.-F. Yang, C.-C. Lai, J.-Y. Liu, and Y.-S. Hsieh, "Regulation of matrix metalloproteinase production by cytokines, pharmacological agents and periodontal pathogens in human periodontal ligament fibroblast cultures," Journal of Periodontal Research, vol. 37, no. 3, pp. 196-203, 2002.

[40] L. X. Shen, J. P. Basilion, and V. P. Stanton Jr., "Single-nucleotide polymorphisms can cause different structural folds of mRNA," Proceedings of the National Academy of Sciences of the United States of America, vol. 96, no. 14, pp. 7871-7876, 1999.

[41] A. C. Pereira, E. Dias do Carmo, M. A. Dias da Silva, and L. E. Blumer Rosa, "Matrix metalloproteinase gene polymorphisms and oral cancer," Journal of Clinical and Experimental Dentistry, vol. 4, no. 5, pp. e297-e301, 2012. 
[42] J. Rollin, S. Régina, P. Vourc'h et al., "Influence of MMP-2 and MMP-9 promoter polymorphisms on gene expression and clinical outcome of non-small cell lung cancer," Lung Cancer, vol. 56, no. 2, pp. 273-280, 2007.

[43] Y. Li, D.-L. Sun, Y.-N. Duan et al., "Association of functional polymorphisms in MMPs genes with gastric cardia adenocarcinoma and esophageal squamous cell carcinoma in high incidence region of North China," Molecular Biology Reports, vol. 37, no. 1, pp. 197-205, 2010.

[44] C. Saracini, P. Bolli, E. Sticchi et al., "Polymorphisms of genes involved in extracellular matrix remodeling and abdominal aortic aneurysm," Journal of Vascular Surgery, vol. 55, no. 1, pp. 171-179.e2, 2012.

[45] C. Yu, Y. Zhou, X. Miao, P. Xiong, W. Tan, and D. Lin, "Functional haplotypes in the promoter of matrix metalloproteinase2 predict risk of the occurrence and metastasis of esophageal cancer," Cancer Research, vol. 64, no. 20, pp. 7622-7628, 2004.

[46] M. R. Luizon and V. de Almeida Belo, "Matrix metalloproteinase (MMP)-2 and MMP-9 polymorphisms and haplotypes as disease biomarkers," Biomarkers, vol. 17, no. 3, pp. 286-288, 2012.

[47] S. B. Kondapaka, R. Fridman, and K. B. Reddy, "Epidermal growth factor and amphiregulin up-regulate matrix metalloproteinase-9 (MMP-9) in human breast cancer cells," International Journal of Cancer, vol. 70, no. 6, pp. 722-726, 1997.

[48] B. Zhang, S. Ye, S.-M. Herrmann et al., "Functional polymorphism in the regulatory region of gelatinase B gene in relation to severity of coronary atherosclerosis," Circulation, vol. 99, no. 14, pp. 1788-1794, 1999.

[49] T.-S. Huang, C.-C. Lee, A.-C. Chang et al., "Shortening of microsatellite deoxy(CA) repeats involved in GL331-induced down-regulation of matrix metalloproteinase-9 gene expression," Biochemical and Biophysical Research Communications, vol. 300, no. 4, pp. 901-907, 2003.

[50] K. Komosinska-Vassev, P. Olczyk, K. Winsz-Szczotka, K. Kuznik-Trocha, K. Klimek, and K. Olczyk, "Age- and genderdependent changes in connective tissue remodeling: physiological differences in circulating MMP-3, MMP-10, TIMP-1 and TIMP-2 level," Gerontology, vol. 57, no. 1, pp. 44-52, 2010.

[51] R. C. Borghaei, P. L. Rawlings Jr., M. Javadi, and J. Woloshin, "NF- $\kappa$ B binds to a polymorphic repressor element in the MMP3 promoter," Biochemical and Biophysical Research Communications, vol. 316, no. 1, pp. 182-188, 2004.

[52] J. Decock, J.-R. Long, R. C. Laxton et al., "Association of matrix metalloproteinase- 8 gene variation with breast cancer prognosis," Cancer Research, vol. 67, no. 21, pp. 10214-10221, 2007.

[53] A. M. Heikkinen, T. Sorsa, J. Pitkäniemi et al., "Smoking affects diagnostic salivary periodontal disease biomarker levels in adolescents," Journal of Periodontology, vol. 81, no. 9, pp. 12991307, 2010.

[54] H. Ilumets, P. Rytilä, I. Demedts et al., "Matrix metalloproteinases $-8,-9$ and -12 in smokers and patients with Stage 0 COPD," International Journal of Chronic Obstructive Pulmonary Disease, vol. 2, no. 3, pp. 369-379, 2007.

[55] K.-Z. Liu, A. Hynes, A. Man, A. Alsagheer, D. L. Singer, and D. A. Scott, "Increased local matrix metalloproteinase-8 expression in the periodontal connective tissues of smokers with periodontal disease," Biochimica et Biophysica ActaMolecular Basis of Disease, vol. 1762, no. 8, pp. 775-780, 2006.
[56] Z. Zhou, S. S. Apte, R. Soininen et al., "Impaired endochondral ossification and angiogenesis in mice deficient in membranetype matrix metalloproteinase I," Proceedings of the National Academy of Sciences of the United States of America, vol. 97, no. 8, pp. 4052-4057, 2000.

[57] D. Li, Q. Cai, L. Ma et al., "Association between MMP-1 g.1607dupG polymorphism and periodontitis susceptibility: a meta-analysis," PLoS ONE, vol. 8, no. 3, Article ID e59513, 2013.

[58] Y. Pan, D. Li, Q. Cai et al., "MMP-9 -1562C >T contributes to periodontitis susceptibility," Journal of Clinical Periodontology, vol. 40, no. 2, pp. 125-130, 2013. 


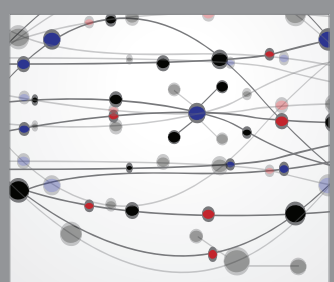

The Scientific World Journal
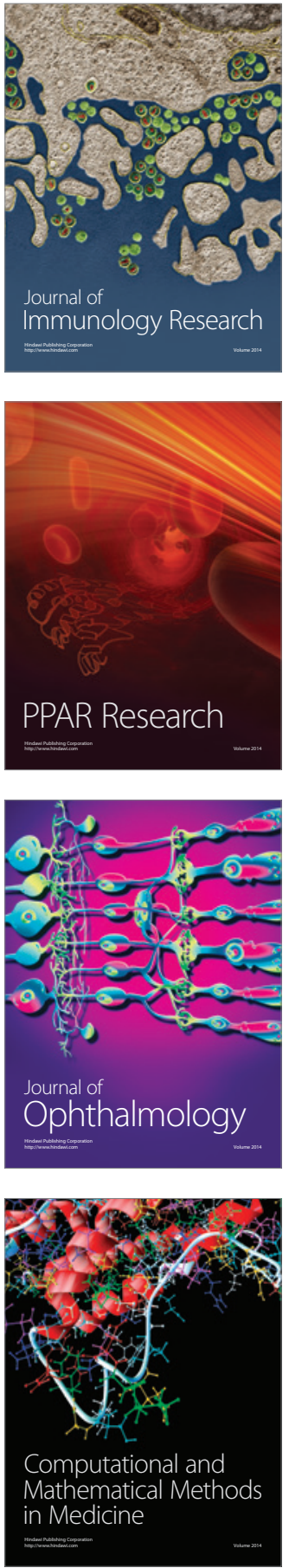

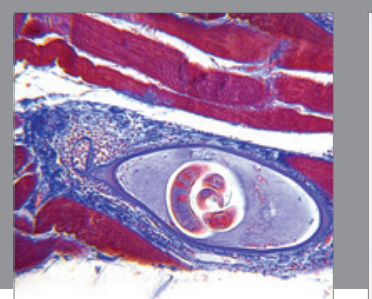

Gastroenterology Research and Practice

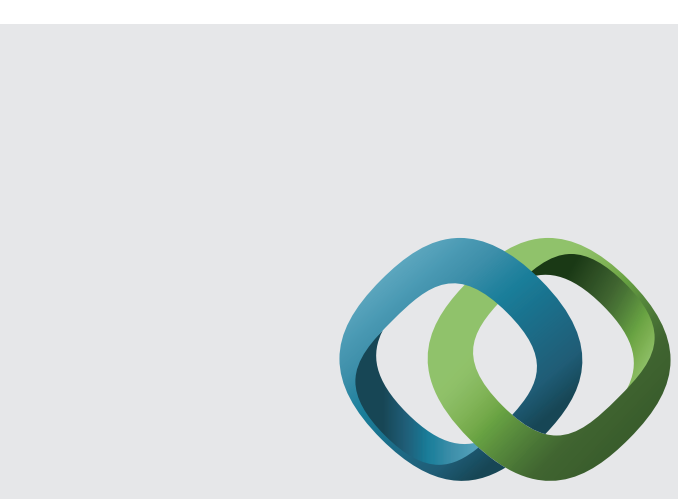

\section{Hindawi}

Submit your manuscripts at

http://www.hindawi.com
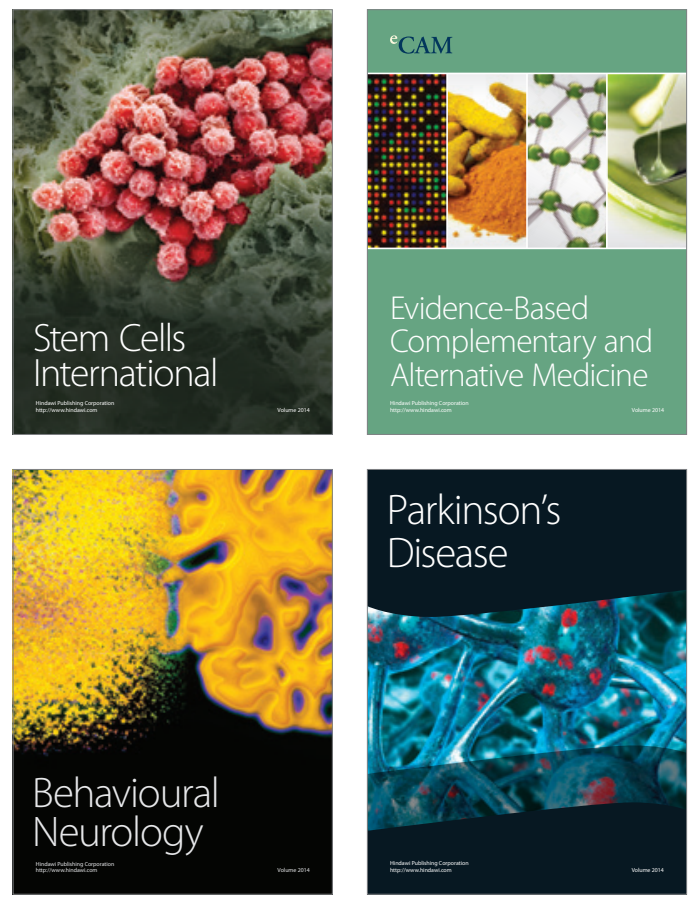
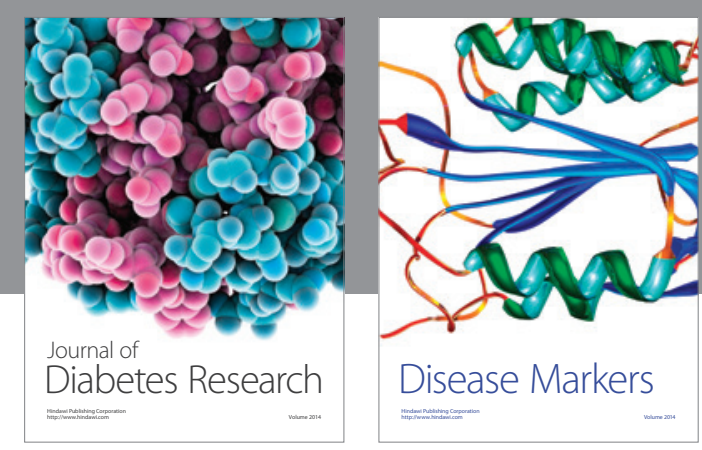

Disease Markers
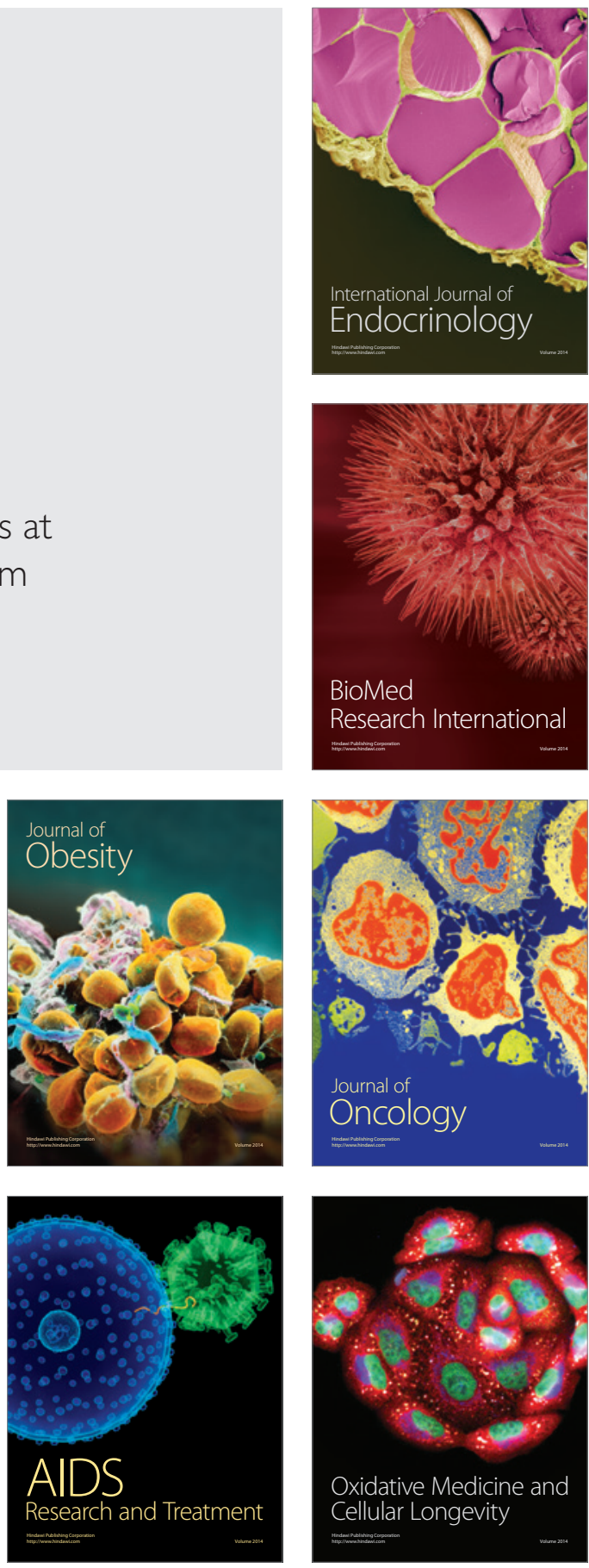